\title{
Clinical and Electroencephalographic Assessment of Diazepam in Liver Disease
}

\author{
IAIN M. MURRAY-LYON， JANET YOUNG，J. D. PARKES R. P. KNILL-JONES, \\ ROGER WILLIAMS
}

British Medical fournal, 1971, 4, 265-266

\section{Summary}

The effects of $5 \mathrm{mg}$ of diazepam intravenously were assessed in 23 patients with liver disease, 10 of whom had clinical evidence either in the past or at the time of study of hepatic encephalopathy. Transient drowsiness occurred in all patients, but prolonged deterioration in conscious level was not observed. Serial electroencephalographic recordings showed the development of activity at faster frequencies, similar to that found in normal subiects, a change which is different from that usually observed in cirrhotic patients after administration of chlorpromazine and morphine when slow-wave activity is increased.

\section{Introduction}

Patients with liver disease are known to be unusually sensitive to certain sedatives and analgesics, particularly paraldehyde and morphine, and hepatic coma may follow their administration (Laidlaw et al., 1961). Nevertheless, sedation may sometimes be necessary in these patients, particularly during the early stages of hepatic encephalopathy when they are often noisy and restless. Sedation may also be required for the alcoholic with delirium tremens who so often has underlying liver disease. Chlorpromazine has been recommended, but Read et al. (1969) showed that this could be followed by a prolonged period of drowsiness accompanied by slowing of the electroencephalogram (E.E.G.). Though phenobarbitone can be useful its effects tend to be cumulative, particularly in renal failure which may complicate severe liver disease. The sedative diazepam (Valium), which has proved safe in a variety of other clinical situations, seemed to us to have a number of potential advantages in the patient with liver disease, and in this paper we report a clinical and electroencephalographic assessment of its effects.

\section{Patients and Methods}

The clinical diagnosis of the 23 patients examined, confirmed by needle biopsy in each case, were as follows: alcoholic cirrhosis (6), cryptogenic cirrhosis (5), active chronic hepatitis with cirrhosis (4), primary biliary cirrhosis (1), viral hepatitis (2), hepatic neoplasm (3), chronic Budd-Chiari syndrome (1), and obstructive jaundice (1). In 10 of the 16 cirrhotic patients there had been a previous episode of hepatic precoma and three of these were in grade I hepatic encephalopathy (Trey et al., 1966) at the time of study. Diazepam was given as a 5-mg dose intravenously over five minutes. \footnotetext{
Medical Research Council Group on Metabolism and Haemo-
dvnamies of Liver Disease, and Devartment of Neurology, King's dvnamies of Liver Disease, and Depart
College Hospital, London, SE5 8RX

IAIN M. MURRAY-LYON, B.SC., M.R.C.P.(LOND., ED.), Senior Medical Registrar

JANET YOUNG, Research Assistant

J. D. PARKES, M.D., M.R.C.P., Senior Registrar in Neurology

R. P. KNILL-JONES, M.SC., M.R.C.P., Formerly Research Fellow, Liver R. P. Tit

ROGER WILLIAMS, M.D., F.R.C.P., Consultant Physician and Director of Liver Unit
}

The technique of E.E.G. recording and automatic wave form analysis is described in detail elsewhere (Parkes et al., 1970). E.E.G. analysis of parieto-occipital activity from both hemispheres was made. The voltage of 20 individual frequencies was summated during a 10-second period, and from the analysis print-out the mean dominant frequency (M.D.F.) for each period was calculated. This method of calculation includes frequency bands between 2 and $33 \mathrm{c} / \mathrm{s}$. The method of Laidlaw and Aitken (1966), in which a mean dominant frequency was calculated with only those frequencies of greater than average abundance, was also used. The latter, since it allows for a skew distribution of frequencies, has been termed in this paper "skew mean dominant frequency." As it is usually determined from only three to five frequencies, it is generally less affected than is the mean dominant frequency by slow and fast frequency artefacts in the recording. The slow-wave index, a measure of relative and absolute activity at 2-3 c/s, was also calculated (Laidlaw and Aitken, 1966).

\section{Results}

All 23 patients became drowsy for up to one and a half hours after the diazepam, but their ability to write and draw a fivepointed star at one hour was unimpaired when compared with a test immediately before administration of the drug. No prolonged deterioration in conscious level was noted and the clinical response was no different in the 10 patients with current or previous clinical evidence of encephalopathy.

Comparison of the E.E.G. indices showed a significantly greater slow-wave index $(P \leqslant 0.05)$ in patients with previous hepatic encephalopathy compared with those without (see Table). The skew mean dominant frequency was lower in the encephalopathy group, indicating a greater prevalence of slow

Calculated E.E.G. Indices before and One Hour after Diazepam in Patients without and with Clinical Evidence of Hepatic Encephalopathy either in the Past or at the Time of Study. Two were Studied on more than One Occasion. Values for Right and Left Hemispheres are Summed (Mean \pm 1 S.D.)

\begin{tabular}{|c|c|c|c|c|c|c|c|}
\hline & \multirow{2}{*}{$\begin{array}{l}\text { No. of } \\
\text { Stud- } \\
\text { ies }\end{array}$} & \multicolumn{2}{|c|}{ Slow-wave Index } & \multicolumn{2}{|c|}{ Skew M.D.F. } & \multicolumn{2}{|c|}{ M.D.F. } \\
\hline & & Before & After & Before & After & Before & After \\
\hline $\begin{array}{l}\text { No encephalo- } \\
\text { pathy } \\
\text { Present or past } \\
\text { encephalo- } \\
\text { pathy }\end{array}$ & 12 & $\begin{array}{c}9 \cdot 3 \pm 9 \\
20 \cdot 5 \pm 21\end{array}$ & $\begin{array}{c}5 \cdot 5 \pm 5 \\
15 \cdot 5 \pm 19\end{array}$ & $\begin{array}{l}9 \cdot 1 \pm 4 \\
6 \cdot 8 \pm 4\end{array}$ & $\begin{array}{l}11 \cdot 5 \pm 3 \\
7 \cdot 1 \pm 3\end{array}$ & $\begin{array}{l}11 \cdot 0 \pm 2 \\
11 \cdot 1 \pm 2\end{array}$ & $\begin{array}{l}11 \cdot 3 \pm 2 \\
11 \cdot 2 \pm 2\end{array}$ \\
\hline
\end{tabular}

frequencies, though the difference did not achieve statistical significance. After diazepam visual analysis showed a pronounced increase in fast frequencies in the recordings from all patients. This was reflected in changes in the slow-wave index and skew mean dominant frequency in those with and without encephalopathy, though in neither instance did the changes after diazepam achieve statistical significance. However, as a result of the greater rise in skew mean dominant frequency in those without encephalopathy than in those with there was in the post-diazepam records a statistically significant difference in skew mean dominant frequency between these two groups $(P<0.05)$. 


\section{Discussion}

Diazepam has been shown to have sedative, muscle relaxant, and anticonvulsant properties. The intravenous administration of $5-15 \mathrm{mg}$ in a variety of non-hepatic disorders is safe and without clinically significant haemodynamic, respiratory, or metabolic changes. Recovery is usually complete within 90 minutes of its administration (Healy et al., 1970). Study of the disappearance curve of diazepam from the blood after oral and parenteral administration (Schwartz et al., 1965; de Silva et al., 1966) indicates rapid and extensive uptake by tissues with an overall drug half-life of two to three days, and if $30 \mathrm{mg}$ orally is given daily there is a progressive increase in plasma diazepam levels (de Silva et al., 1966). In keeping with this are the effects of diazepam on the E.E.G. which may take some days to develop fully during continued administration and may persist for some days after discontinuation of the drug (Towler et al., 1962; Metcalfe and Whitley, 1964). The main change in the E.E.G. observed in normal subjects is the apbearance of low to moderate voltage fast activity first in the frontal areas and spreading posteriorly with a reduction in amplitude of normal alpha rhythm.

Though the major site of metabolic breakdown of diazepam by demethylation, hydroxylation, and conjugation is in the liver, the response of our patients with liver disease does not differ from that reported for normal subjects (Healy et al., 1970). In particular drowsiness was not prolonged or exaggerated even in those with hepatic encephalopathy. A reduction in E.E.G. dominant frequency and an increase in slow-wave activity give some index of the severity of liver disease (Laidlaw and Read, 1963), and our patients with hevatic encephalopathy either in the vast or at the time of study showed the most pronounced E.E.G. changes. Even in these patients, however, there was no tendency to develop increased slow activity in the E.E.G. as has been described after morphine or chlorpromazine.
The results of present studies show that a single injection of $5 \mathrm{mg}$ of diazepam is safe when assessed both clinically and by serial E.E.G. recordings in a group of patients with relatively well compensated chronic liver disease. We have also had some clinical experience of it in patients with fulminant hepatic failure. It can be of value in controlling the epileptic convulsions that these patients so often have. A dose of $5 \mathrm{mg}$ intravenously given slowly over 10 minutes is sufficient on most occasions, but this dosage may be repeated after 30 minutes and then up to four-hourly. With such a regimen we have sometimes observed depression of respiration-a hazard to which these patients are particularly prone-and careful monitoring is essential.

We are grateful to Dr. K. J. Zilkha for his support and to Mrs. $M$. Roome for valuable technical help. The King's College Hospital Research Trust gave generous financial support.

\section{References}

de Silva, J. A., Koechlin, B. A., and Bader, G. (1966). Fournal of Pharmaceutical Sciences, 55, 692.

Healy, T. E. J., Robinson, J. S., and Vickers, M. D. (1970). British Medical

Laidlaw, J., and Aitken, R. (1966). Electroencephalography and Clinical Neurophysiology, 21, 202 .

Laidlaw, J., and Read, A. E. (1963). Clinical Science, 24, 109.

Laidlaw, J., Read, A. E., and Sherlock, S. (1961). Gastroenterology, 40, 389. Metcalf, D. R., and Whitley, D. J. (1964). American fournal of Psychiatry, $120,1114$.

Parkes, J. D., Murray-Lyon, I. M., and Williams, R. (1970). Quarterly Fournal of Medicine, 39; 515

Read, A. E., Laidlaw, J., and McCarthy, C. F. (1969). British Medical fournal, 3, 497.

Schwartz, M. A., Koechlin, B. A., Postma, E., Palmer, S., and Krol, G. (1965). Fournal of Pharmacology and Experimental Therapeutics, 149, 423. Towler, M. L., Beall, B. D., and King, J. B. (1962). Southern Medical fournal, 55, 832. Trey, C., Burns, D. G., and Saunders, S. J. (1966). New England Fournal of

\title{
Use of Metolazone in the Treatment of Ascites due to Liver Disease
}

\author{
P. HILLENBRAND, SHEILA SHERLOCK
}

British Medical fournal, 1971, 4, 266-270

\section{Summary}

In 8 out of 20 patients with chronic liver disease ascites was controlled with metolazone, 10 required additional amiloride or spironolactone to achieve control, and 2 were resistant to all diuretic therapy. An initial dose of $5 \mathrm{mg}$ daily is suggested, though much higher doses may be required ultimately. When metolazone is used alone the high incidence of hypokalaemia $(80 \%)$, hypochloraemia (35\%), and encephalopathy (35\%) compared with the results of other series is a major disadvantage and indicates that this drug should be used with caution in patients with liver disease. Hypokalaemia can usually be prevented by the simultaneous administration of amiloride or spironolactone. The low incidence of azotaemia (5\%) suggests that this diuretic may be useful if renal function is particularly impaired.

Department of Medicine, Royal Free Hospital, London WC1X 8LF P. HILLENBRAND, M.R.C.P., Honorary Assistant Lecturer SHEILA SHERLOCK, M.D., F.R.C.P. (LOND., ED.), Professor of Medicine

\section{Introduction}

Metolazone is a quinazolinone diuretic, chemically related to quinethazone. Its action resembles that of thiazides, though animal experiments indicate that it is more potent and less kaliuretic. Diuresis begins within two hours and persists for 24 hours in normal subjects. Dose-response studies in normal subjects show that a maximum diuretic activity is observed on raising the dose to $10 \mathrm{mg}$. The purpose of this study was to determine the efficacy of metolazone in controlling ascites due to liver disease and to assess the incidence of complications, particularly electrolyte disturbance.

\section{Patients and Methods}

Twenty patients with chronic liver disease and persistent ascites were studied (Table I). They were put to bed, weighed daily, and given a $22-\mathrm{mEq}$ sodium diet. Fluid intake was restricted to $1,000 \mathrm{ml}$ a day. Protein intake was $60-70 \mathrm{~g}$ except during episodes of encephalopathy. Fluid intake and output and 24-hour urine sodium, potassium, and chloride were measured. Blood urea, electrolytes liver function tests, 